\title{
Urine albumin excretion: Characterization of normal variability in healthy children*
}

\author{
John Robert Brandt", Craig Stephen Wong, Aaron Jacobs, Amy Otten Staples
}

School of Medicine, University of New Mexico, Albuquerque, USA

Email: \#ibrandt@salud.unm.edu

Received 6 March 2013; revised 5 April 2013; accepted 12 April 2013

Copyright (C) 2013 John Robert Brandt et al. This is an open access article distributed under the Creative Commons Attribution License, which permits unrestricted use, distribution, and reproduction in any medium, provided the original work is properly cited.

\section{ABSTRACT}

Objective: Elevated urine albumin to creatinine ratio (ACR) of $>30 \mathrm{mg} / \mathrm{gm}$ is a widely agreed upon indicator of pathologic albuminuria in children. However, the most reliable specimen to measure ACR in children remains undefined. We assess the range and limits of upright and supine total albumin and ACR in healthy children. Methods: Healthy children age 6 18 years completed 24-hour and split upright and supine urine collections. Upright, supine and 24-hour protein, albumin and creatinine were measured. Primary outcomes are range and variation in urine albumin by diurnal status, age, gender, BMI percentile and Tanner stage. Results: In healthy children, with mean age 12.9 year (sd 3.2), upright ACR was 2-fold greater than supine (13.9 vs $6.8 \mathrm{mg} / \mathrm{gm}, \mathrm{p}=\mathbf{0 . 0 2})$. The range of ACR was much greater in the upright (2 $323 \mathrm{mg} / \mathrm{gm})$ compared to the supine $(1.7$ - $76 \mathrm{mg} / \mathrm{gm})$ samples. The average total 24-hour urine albumin was $8.4 \mathrm{mg}$ (sd 9.8) and the mean ACR was $8.9 \mathrm{mg} / \mathrm{gm}$ (sd 11.7). The 24-hour albumin increased with age and Tanner stage, but this relationship was not significant after adjusting for BSA or urine creatinine. A supine or upright ACR of $>30 \mathrm{mg} / \mathrm{gm}$ was found in $5.4 \%$ of each group. However, in all subjects with an elevated ACR on an individual upright or supine sample, a second 1st am ACR sample was normal. Conclusions: In healthy children there is a marked diurnal variability in ACR with a higher value from a daytime sample compared to 1st morning specimen. Screening for pathologic albuminuria should always use a first morning urine specimen.

Keywords: ACR; Albuminuria; Albumin to Creatinine

\footnotetext{
*Funding source: UNM GCRC \# 5M01 RR00997.

"Corresponding author.
}

Ratio; Microalbuminuria; Proteinuria

\section{INTRODUCTION}

Urine albumin excretion is widely used as a marker for the progression of chronic kidney disease in both adults and children [1,2] and of future cardiovascular disease risk in adults $[3,4]$. The increasing prevalence of childhood obesity, hypertension and metabolic syndrome over the last 30 years $[5,6]$ predicts a future healthcare system burdened with cardiovascular, diabetic and kidney disease; conditions in which urinary albumin excretion is an important marker of the clinical course of disease and the impact of therapeutic interventions. Recently, the National Kidney Foundation has recommended that the chronic kidney disease classification system should be modified to include the presence of albuminuria [7], emphasizing the critical importance of albuminuria in the prognosis of patients with chronic kidney disease.

Albumin excretion is most accurately described using 24 hours urine collection, but this test is cumbersome and prone to collection error. Because of these issues, albuminuria is most commonly measured by a randomly collected urinary albumin to creatinine (ACR) ratio $[8,9]$. The first morning urine albumin collection has been promoted as the most accurate sample to use in detecting children with pathologic proteinuria [9]. Albumin excretion in children has been variously reported to be influenced by age, gender, pubertal stage and body mass [3, 10-14]. However, the 24-hour diurnal variability in both total urine albumin and ACR in children has not been widely studied.

Among normal pediatric subjects in New Mexico, without acute or chronic illness, we sought to primarily characterize the diurnal variability of urinary ACR. Secondary, aims of the study were to characterize associations between albumin excretion with age, gender, body mass index and pubertal stage. 


\section{METHODS}

\subsection{Study Population}

This prospective cohort study was designed to examine the range of normal urine albumin excretion in healthy children. Inclusion criteria included age $6-18$ years at enrollment, urinary continence, and ability to provide assent/consent. Exclusion criteria were children with temperature greater than $37.9^{\circ} \mathrm{C}$, metabolic, circulatory, or liver disease, a known history of urinary tract infections, renal disease or any chronic illness known to have renal involvement, and strenuous exercise 24 hours prior to the study. The study protocol was reviewed and approved by the Human Research Review Committee at the University of New Mexico.

Investigations were performed at the University of New Mexico's General Clinical Research Center (GCRC). Children were admitted in the evening prior to the study day. Age, gender, height weight, blood pressure and temperature were recorded. A recent symptom history was taken and physical exam performed by an investigator to assess for recent or acute illness. Blood pressure was measured each morning and evening for a total of 4 measures.

The morning following admission, immediately upon arising, the subject's urine was collected for albumin, total protein and creatinine measurement and a blood sample for serum creatinine was obtained. The time of this initial void was recorded as the start of the 24-hour timed urine collection for albumin, total protein and creatinine. Subjects were allowed out of their beds and permitted to ambulate or remain in their rooms in a bed or chair. No strenuous physical activity was permitted. All urine following the first morning void was collected until the child retired for sleep, with a final sample taken just prior to laying down to sleep. This sample was labeled; "Upright urine".

A second collection was initiated once the subjects went to sleep for the evening. If there was a need to void overnight, the urine sample was collected at the bedside in this second collection. Upon awakening the following morning, the final urine sample was collected. Time of final void and vital signs were recorded. The subjects were then discharged. This second collection was labeled; "Supine urine". The total volume of each urine collection was recorded and samples taken for measurement of urine creatinine, protein and albumin concentration. Subject's pubertal stage was determined using a validated self-assessment questionnaire for Tanner staging [15].

Subjects were excluded from analysis if found to have non-orthostatic proteinuria (suggesting pathologic proteinuria).

\subsection{Definition of Terms}

Urine albumin (UrAlb), total protein (UrTP) and creatinine $(\mathrm{UrCr})$ excretion are expressed as total $\mathrm{mg}$ per 24 hours and as urinary albumin to creatinine ratio (ACR) in milligram albumin per gram creatinine. In order to allow for comparison of individuals of varying body size, urine albumin (UrAlb) was also adjusted for standardized body surface area (BSA) in meter squared $\left(1.73 \mathrm{~m}^{2}\right)$.

Variability is expressed as range, standard deviation (sd) or upper limit of the $95 \%$ confidence interval (UL $95 \% \mathrm{CI})$. The UL $95 \% \mathrm{CI}$ is used to express the maximum value expected in the healthy population. UrAlb was considered to be elevated if $>30 \mathrm{mg} / 1.73 \mathrm{~m}^{2} / 24$ hours. Urine total protein (UrTP) was considered elevated if $>100 \mathrm{mg} / \mathrm{m}^{2} / 24$ hours [16].

Orthostatic Proteinuria (OP) was defined as a 24-hour UrTP excretion rate $>100 \mathrm{mg} / \mathrm{m}^{2} / 24$ hours with a normal supine UrTP excretion rate $\left(<4 \mathrm{mg} / \mathrm{m}^{2} /\right.$ hour $)$ [16]. Any subject whose total protein exceeded established norms, including those with $\mathrm{OP}$, were referred to their personal physician for further evaluation. BSA was calculated using the geometric method [17]. Body mass index (BMI) was calculated as weight $(\mathrm{kg})$ divided by height $\mathrm{t}^{2}\left(\mathrm{~m}^{2}\right)$. The BMI percentile was calculated using the methods established by the Centers for Disease Control and Prevention 2000 growth charts [18].

\subsection{Laboratory Assays}

All laboratory studies were performed at the central clinical laboratories at the University of New Mexico Hospital. Urine albumin was measured using a turbometric/immunoturbometric method (Ortho clinical diagnostics, Rochester, NY, USA). This assay's limit of detection is $0.6 \mathrm{mg} / \mathrm{dl}$. When urine albumin was below this limit the sample was assigned a value of $0.3 \mathrm{mg} / \mathrm{dl}$. Urine Creatinine (UrCr) was measured using an enzymatic, isotope dilution mass spectroscopy traceable method (Ortho clinical diagnostics, Rochester, NY, USA). Urine total protein (UrTP) concentration $(\mathrm{mg} / \mathrm{dl})$ was measured using a pyrocatechol violet method (Ortho clinical diagnostics, Rochester, NY, USA). UrTP assay's limit of detection is $5 \mathrm{mg} / \mathrm{dl}$. When urine protein was below this limit the sample was assigned a value of $2.5 \mathrm{mg} / \mathrm{dl}$.

\subsection{Statistical Analysis}

We used two-sided beta expectation tolerance intervals for normally distributed data to estimate that the sample size of 103 subjects was optimal to establish a range of normal values [19]. Total, upright or supine samples were available in 111 subjects. Paired t-test was used to examine albumin excretion in groups defined by the dichotomous variables gender, BMI percentile, and diurnal status (supine and upright) for normally distributed data. 
The Kruskal-Wallis rank test was used for comparing variables with three or more groups (Age and Tanner stage). Linear regression using a stepwise model ( $p$-value for removal $=0.20, \mathrm{p}$ for inclusion 0.05 ) was used to evaluate variables predicting 24-hour urine albumin excretion. Ordinal data was compared using tests of proportions. Results were analyzed by age, BMI, gender and Tanner stage. The threshold for significance was set to a p-value less than or equal to 0.05. STATA v12.0 (College Station TX, USA) was used for all analyses and SPSS v19 (SPSS, IBM Inc, Somers, NY, USA) was used for graphical display of data. All statistical tests were two-tailed.

\section{RESULTS}

\subsection{Subjects}

Between August 2005 and November 2008, subjects were enrolled from an urban area in the southwestern United States. A total of 139 subjects were enrolled for 24-hour urine studies. 27 were excluded for incomplete specimens. One subject was excluded for non-orthostatic proteinuria (563 mg/day). At study completion 75 subjects with 24 hours timed paired upright and supine ACR were available for analysis. An additional 22 subjects had complete paired upright and supine ACR samples $(\mathrm{n}=97)$, but inadequate data on collection duration to calculate 24-hour data. A supine or upright ACR was available in 111 subjects. Subjects were of Hispanic and non-Hispanic Caucasian ethnicity. Boys comprised $60 \%$ of the study group. Mean age was 12.9 years (sd 3.2) with a range of 6 to 18 years at enrollment. Tanner Stage distribution was; Stage 1:13\%, 2:15\%, 3:18\%, 4:30\%, and $5: 22 \%$. A BMI $\geq 85$ th percentile was present in $33 \%$ with no gender bias. A BMI $>95 \%$ was seen in $19 \%$ of all subjects, in $26 \%$ in boys and $19 \%$ in girls $(\mathrm{p}=\mathrm{ns})$. Mean blood pressure was 109/62 (sd 11.5/5.6) $\mathrm{mmHg}$. Serum creatinine was within the normal range for all subjects with a mean of $0.7(\mathrm{sd} 0.14) \mathrm{mg} / \mathrm{dl}$.

\subsection{4-Hour Albumin Excretion}

Mean total UrAlb excretion for all subjects was 8.4 (95\% CI 6.2 - 10.7) $\mathrm{mg}$ per 24 hours. UrAlb adjusted for body surface area (BSA) was 9.3 (95\%CI 6.7 - 12.0) $\mathrm{mg} / 1.73 \mathrm{~m}^{2}$ per 24 hours. Mean 24-hour ACR was 8.9 (95\%CI 6.2 - 11.6) mg/gm (Table 1). Unadjusted Albumin excretion showed a significant increase with age $(p$ $<0.05$ ). However, after adjusting for BSA or urine creatinine $(\mathrm{UrCr})$, no statistically significant trend was seen. The UrAlb was higher at the extremes of the Tanner staging (stages 1 and 5), but lower for the middle stages (stages 2-4). There was no effect of gender or BMI percentile seen on any measure of albumin excretion. A stepwise linear regression model was performed with covariates 24-hour UrCr, age, gender, Tanner stage and BMI percentile with $\mathrm{p}$ value for removal of 0.2 . Only 24-hour total $\mathrm{UrCr}$ was significantly associated with 24 hour albumin excretion $(\mathrm{p}<0.01)$.

\subsection{Diurnal Albumin Excretion}

Paired upright and supine ACR samples were available in 97 subjects. Upright urine had a higher ACR compared to paired supine samples. (13.9 vs $6.8 \mathrm{mg} / \mathrm{gm}, \mathrm{p}=$ 0.02) (Figure 1). The 95\%CI for upright ACR was 6.9 $21 \mathrm{mg} / \mathrm{gm}$ and for supine ACR was $4.7-8.8 \mathrm{mg} / \mathrm{gm}$. This diurnal variability was consistent across gender, age and BMI percentile groups (Table 2). The total range of ACR was greater in the upright $(1.4-323 \mathrm{mg} / \mathrm{gm})$ than supine ACR (1.6 - $76 \mathrm{mg} / \mathrm{gm})$ samples.

Two supine ACR specimens were available for each patient; a random 1st am sample collected prior to starting the 24-hour urine collection and the overnight collection completed the following morning. The correlation between these samples was modest $(r=0.44)$. Paired values showed a random $1 \mathrm{st}$ am ACR of $5.0 \mathrm{mg} / \mathrm{gm}(\mathrm{sd}$ 3.8) vs, an overnight supine ACR of $7.3 \mathrm{mg} / \mathrm{gm}$ (sd 10.9) $(\mathrm{p}=0.02)$. However, if samples were stratified by $24-$ hour ACR into high $(>20 \mathrm{mg} / \mathrm{gm})$ vs low $(\leq 20 \mathrm{mg} / \mathrm{gm})$ groups we found essentially no variability in sequential daily specimens in the low-normal group (4.6 vs 4.5 $\mathrm{mg} / \mathrm{gm}, \mathrm{p}=0.4, \mathrm{n}=78$ ) while the high-normal group ( $\mathrm{n}$ $=10$ ) accounted for the majority of day to day variability ( 27.7 vs $8.1 \mathrm{mg} / \mathrm{gm}, \mathrm{p}=0.02$ ). No subject had concurrent elevations of both supine and 1st am ACR.

\subsection{Outliers, Unpaired Data and Characterization of Elevated ACR}

An elevated upright ACR (>30 mg/gm) was seen in 5.4\%

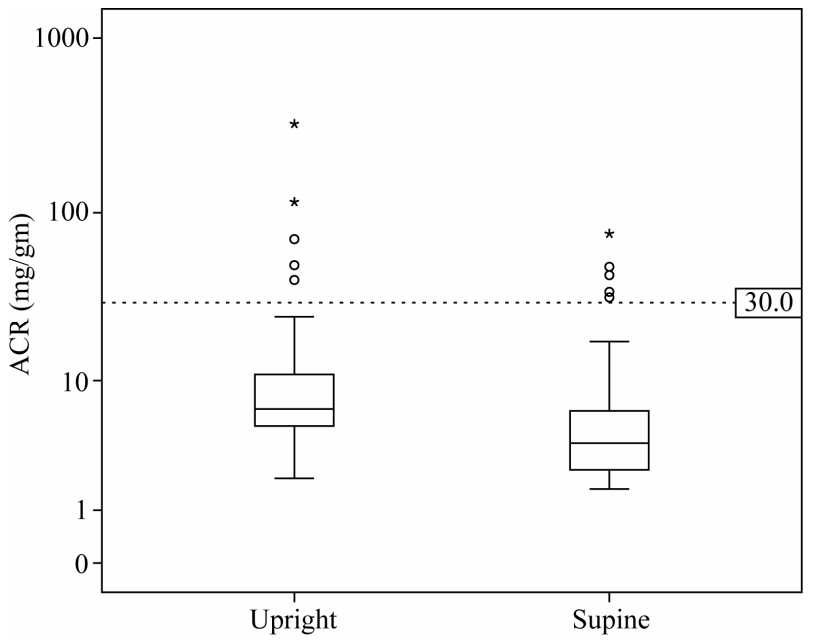

Figure 1. Upright and supine ACR (mg/gm). 
Table 1. 24-hour total urine albumen (UrAlb), UrAlb adjusted for body surface area and urine albumin to creatinine ratio (ACR), mean and (sd).

\begin{tabular}{|c|c|c|c|c|c|c|}
\hline & $\mathrm{N}$ & UrAlb mg/day & $\mathrm{N}$ & $\mathrm{UrAlb} \mathrm{mg} / 1.73 \mathrm{~m}^{2} /$ day & $\mathrm{N}$ & Ur ACR mg/gm \\
\hline All & 76 & $8.4(9.8)$ & 71 & $9.3(11.1)$ & 75 & $8.9(11.7)$ \\
\hline \multicolumn{7}{|l|}{ Gender } \\
\hline Male & 45 & $8.6(9.6)$ & 42 & $8.4(5.7)$ & 44 & $7.8(7.4)$ \\
\hline Female & 31 & $8.2(10.2)$ & 29 & $10.6(16.2)$ & 31 & $10.4(15.9)$ \\
\hline \multicolumn{7}{|l|}{ Age years } \\
\hline 6 to 10 & 22 & $6.5(11.3)$ & 20 & $10.5(18.4)$ & 22 & $11.4(12.1)$ \\
\hline 11 to 14 & 31 & $8.2(6.8)$ & 30 & $9.1(7.5)$ & 31 & $7.0(5.0)$ \\
\hline 15 to 19 & 23 & $10.6(11.6)^{*}$ & 21 & $8.6(6.0)$ & 22 & $9.0(10.3)$ \\
\hline \multicolumn{7}{|l|}{ BMI } \\
\hline$<85 \%$ & 47 & $7.4(8.5)$ & 47 & $9.2(12.6)$ & 46 & $8.6(13)$ \\
\hline$\geq 85 \%$ & 23 & $9.0(7.6)$ & 23 & $9.7(8.2)$ & 23 & $8.0(5.4)$ \\
\hline \multicolumn{7}{|l|}{ Tanner } \\
\hline 1 & 11 & $9.1(15.6)$ & 9 & $15.9(27)$ & 11 & $16.3(25)$ \\
\hline 2 & 11 & $4.0(2.2)$ & 11 & $5.5(3.2)$ & 11 & $5.6(2.3)$ \\
\hline 3 & 12 & $6.4(4.2)$ & 12 & $7.5(4.2)$ & 12 & $6.8(3.1)$ \\
\hline 4 & 24 & $9.2(7.1)$ & 23 & $9.9(7.9)$ & 24 & $7.6(5.3)$ \\
\hline 5 & 17 & $11.3(13.5)^{*}$ & 16 & $8.8(6.8)$ & 16 & $10.1(11.9)$ \\
\hline
\end{tabular}

Table 2. Albumin to creatinine ratio (ACR) mg/gm, mean (sd).

\begin{tabular}{|c|c|c|c|c|}
\hline & \multirow{2}{*}{$\mathrm{N}$} & \multicolumn{2}{|c|}{$\mathrm{ACR}(\mathrm{mg} / \mathrm{gm})$} & \multirow{2}{*}{ p-value } \\
\hline & & Upright & Supine & \\
\hline Control & 97 & $13.9(34.9)$ & $6.8(10.3)$ & 0.02 \\
\hline \multicolumn{5}{|l|}{ Age (yrs) } \\
\hline 6 to 10 & 26 & $9.5(5.3)$ & $8.5(14.2)$ & 0.4 \\
\hline 11 to 14 & 44 & $18.6(7.6)$ & $6.9(10.2)$ & 0.06 \\
\hline 15 to 19 & 26 & $10.6(13.9)$ & $4.9(4.4)$ & 0.02 \\
\hline \multicolumn{5}{|l|}{ Gender } \\
\hline M & 58 & $11.1(16.9)$ & $7.1(12.3)$ & 0.07 \\
\hline $\mathrm{F}$ & 39 & $18.2(51.1)$ & $6.3(6.4)$ & 0.07 \\
\hline \multicolumn{5}{|l|}{ BMI } \\
\hline$<85 \%$ & 59 & $14.5(41.8)$ & $6.8(11.3)$ & 0.08 \\
\hline$\geq 85 \%$ & 29 & $8.1(4.8)$ & $6.9(9.5)$ & 0.3 \\
\hline \multicolumn{5}{|l|}{ Tanner } \\
\hline 1 & 13 & $12.7(6.7)$ & $15.0(22)$ & 0.4 \\
\hline 2 & 15 & 9.5 (11.6) & $5.1(3.6)$ & 0.08 \\
\hline 3 & 18 & $26.6(74.3)$ & $4.6(3.5)$ & 0.1 \\
\hline 4 & 28 & $7.3(3.9)$ & $7.1(9.5)$ & 0.5 \\
\hline 5 & 22 & $16.2(27.1)$ & $4.7(4.4)$ & 0.03 \\
\hline
\end{tabular}


$(\mathrm{n}=6$, mean 105, range $32-323)$ of all subjects with an upright sample $(\mathrm{n}=111)$. Paired supine ACR was available for 5 of these upright samples, all of which were normal. In 4 of these $5(67 \%)$, concurrent paired urine total protein samples indicated orthostatic proteinuria was present. An elevated supine ACR was also seen in $5.4 \%(\mathrm{n}=6$ mean 46 , range 32 to $323 \mathrm{mg} / \mathrm{gm})$ of all supine samples $(n=110)$. None of the elevated supine urines had an elevation of the matched upright ACR. Hence, in no subject was both supine and upright ACR elevated concurrently.

When all complete collections were examined $(n=75)$, a 24-hour ACR above the clinical threshold for pathologic albuminuria $(>30 \mathrm{mg} / \mathrm{gm})$ was seen in 2 subjects $(2.7 \%)$. There was no difference in the prevalence of elevated ACR by gender, age or Tanner stage. In both samples with an elevated total ACR, the supine ACR was normal.

\section{DISCUSSION}

This study demonstrates three major findings: first, there is a natural and predictable diurnal variation in urine albumin excretion in healthy children. Albumin excretion is greater during the day when an individual is upright compared to the night when they are at rest. Second, this pattern does not vary appreciably by age, gender, tanner stage or body mass. Third: higher daytime albumin excretion was correlated with higher creatinine excretion.

Urine albumin excretion is an important clinical tool in assessing and following patients with chronic renal disease. Patients with diabetes mellitus, chronic kidney failure and solitary kidneys routinely have urine albumin measured as a marker of sub-clinical renal injury [20-22]. An understanding of the natural variability of urine albumin is critical for the appropriate use and interpretation of this test. Daytime (upright) urine albumin excretion exceeds nighttime (supine) excretion by $50 \%-100 \%$. In healthy children, a single random upright or supine ACR, will be elevated in about $5 \%$ of samples. This variation must be taken into account when interpreting urine ACR specimens.

Past studies have shown a similar variation in ACR levels between recumbency and ambulation or between rest and physical activity $[13,23]$. In a previous study on orthostatic proteinuria [24] in this cohort of subjects we found that measured $\mathrm{CrCl}$ was higher during the daytime compared to the night and a higher $\mathrm{CrCl}$ was associated with an increased risk of orthostatic proteinuria. Our finding of a correlation between total urine creatinine and albumin excretion suggests that the difference in albumin excretion between day and night may be mediated by changes in glomerular filtration rate.

The day-to-day variability of the supine UrAlb is not insignificant. Sequential 1st am supine samples varied by a mean of $40 \%$ in our subjects. Most of this variation was seen in samples in the high normal range $(>20$ $\mathrm{mg} / \mathrm{gm})$. Interestingly, no subject had an elevated ACR on two sequential supine samples, implying that a child with a single elevated ACR should always have a second sample performed before assuming pathologic proteinuria is present.

In the past there has been conflicting findings regarding a gender difference in albumin excretion. Several studies have shown a higher ACR in girls compared to boys in both 24-hour and diurnal samples [13,23,25]. Houser found a higher ACR in girls only in upright or post exercise urine [23] but not supine samples. Other studies have shown conflicting results [14,26]. We saw a trend to higher ACR and BSA-adjusted UrAlb in girls, but our study power was not adequate to detect a statistical difference. We did not see trends of higher UrAlb with increased BMI and Tanner stage, though these factors have been noted to be predictors of UrALB in some past studies [10,25-27]. It seems clear that gender, pubertal and BMI associated variations in urine albumin excretion in children are in need of further clarification.

In this study, an elevated 24-hour urine albumin excretion was only seen concurrent with a normal supine (nighttime) urine albumin. This raises the question of whether these children have orthostatic proteinuria. Orthostatic proteinuria is a benign increase in daytime urine protein excretion without renal pathology and has been described in $4 \%-20 \%$ of healthy children $[16,24]$. In a previous study by our group, orthostatic proteinuria was associated with a proportional change in creatinine clearance, suggesting that changes in GFR mediate the variation in protein excretion [24]. It seems reasonable to infer that urine albumin may also exhibit a similar benign orthostatic variability in a percentage of healthy individuals. Hence, in healthy individual random upright urine ACR is more likely to show a concerning elevation in ACR compared to a 1st am specimen, leading to unnecessary follow-up testing. We recommend the measurement of urine albumin excretion in children should always utilize a first morning or supine urine collection and be confirmed with 2 samples before embarking on extensive evaluation.

\section{REFERENCES}

[1] Wong, C.S., Pierce, C.B., Cole, S.R., Warady, B.A., Mak, R.H., Benador, N.M., Kaskel, F., Furth, S.L. and Schwartz, G.J. (2009) Association of proteinuria with race, cause of chronic kidney disease, and glomerular filtration rate in the chronic kidney disease in children study. Clinical Journal of American Society of Nephrology, 4, 812 819. doi:10.2215/CJN.01780408

[2] Levey, A.S., Atkins, R., Coresh, J., Cohen, E.P., Collins, 
A.J., Eckardt, K.U., Nahas, M.E., Jaber, B.L., Jadoul, M., Levin, A., Powe, N.R., Rossert, J., Wheeler, D.C., Lameire, N. and Eknoyan, G. (2007) Chronic kidney disease as a global public health problem: Approaches and initiatives-A position statement from kidney disease improving global outcomes. Kidney International, 72, 247-259. doi:10.1038/sj.ki.5002343

[3] Rademacher, E.R. and Sinaiko, A.R. (2009) Albuminuria in children. Current Opinion in Nephrology and Hypertension, 18, 246-251.

[4] Gerstein, H.C., Mann, J.F., Yi, Q., Zinman, B., Dinneen, S.F., Hoogwerf, B., Halle, J.P., Young, J., Rashkow, A., Joyce, C., Nawaz, S. and Yusuf, S. (2001) Albuminuria and risk of cardiovascular events, death, and heart failure in diabetic and nondiabetic individuals. Journal of the American Medical Association, 286, 421-426.

doi:10.1001/jama.286.4.421

[5] Din-Dzietham, R., Liu, Y., Bielo, M.V. and Shamsa, F. (2007) High blood pressure trends in children and adolescents in national surveys, 1963 to 2002. Circulation, 116, 1488-1496.

doi:10.1161/CIRCULATIONAHA.106.683243

[6] Ogden, C.L., Carroll, M.D. and Flegal, K.M. (2008) High body mass index for age among US children and adolescents, 2003-2006. Journal of the American Medical Association, 299, 2401-2405. doi:10.1001/jama.299.20.2401

[7] Levey, A.S., de Jong, P.E., Coresh, J., El Nahas, M., Astor, B.C., Matsushita, K., Gansevoort, R.T., Kasiske, B.L. and Eckardt, K.U. (2011) The definition, classification, and prognosis of chronic kidney disease: A KDIGO controversies conference report. Kidney International, 80, 1728. doi:10.1038/ki.2010.483

[8] Assadi, F.K. (2002) Quantitation of microalbuminuria using random urine samples. Pediatric Nephrology, 17, 107110. doi:10.1007/s00467-001-0762-5

[9] Cowell, C.T., Rogers, S. and Silink, M. (1986) First morning urinary albumin concentration is a good predictor of 24-hour urinary albumin excretion in children with type 1 (insulin-dependent) diabetes. Diabetologia, 29, 97-99. doi:10.1007/BF00456117

[10] Bangstad, H.J., Dahl-Jorgensen, K., Kjaersgaard, P., Mevold, K. and Hanssen, K.F. (1993) Urinary albumin excretion rate and puberty in non-diabetic children and adolescents. Acta Paediatrica, 82, 857-862.

[11] Jones, C.A., Francis, M.E., Eberhardt, M.S., Chavers, B., Coresh, J., Engelgau, M., Kusek, J.W., Byrd-Holt, D., Narayan, K.M., Herman, W.H., Jones, C.P., Salive, M. and Agodoa, L.Y. (2002) Microalbuminuria in the US population: Third national health and nutrition examination survey. American Journal of Kidney Diseases, 39, 445-459. doi:10.1053/ajkd.2002.31388

[12] Ferris, M., Hogan, S.L., Chin, H., Shoham, D.A., Gipson, D.S., Gibson, K., Yilmaz, S., Falk, R.J. and Jennette, J.C. (2007) Obesity, albuminuria, and urinalysis findings in US young adults from the add health wave III study. Clinical Journal of the American Society of Nephrology, 2, 1207-1214. doi:10.2215/CJN.00540107

[13] Davies, A.G., Postlethwaite, R.J., Price, D.A., Burn, J.L.,
Houlton, C.A. and Fielding, B.A. (1984) Urinary albumin excretion in school children. Archives of Disease in Childhood, 59, 625-630. doi:10.1136/adc.59.7.625

[14] Sanchez-Bayle, M., Rodriguez-Cimadevilla, C., Asensio, C., Ruiz-Jarabo, C., Baena, J., Arnaiz, P., Villa, S. and Cocho, P. (1995) Urinary albumin excretion in Spanish children. Nino Jesus Group. Pediatric Nephrology, 9, 428-430. doi:10.1007/BF00866717

[15] Taylor, S.J., Whincup, P.H., Hindmarsh, P.C., Lampe, F., Odoki, K. and Cook, D.G. (2001) Performance of a new pubertal self-assessment questionnaire: A preliminary study. Paediatric and Perinatal Epidemiology, 15, 88-94. doi:10.1046/j.1365-3016.2001.00317.x

[16] Hogg, R.J., Portman, R.J., Milliner, D., Lemley, K.V., Eddy, A. and Ingelfinger, J. (2000) Evaluation and management of proteinuria and nephrotic syndrome in children: Recommendations from a pediatric nephrology panel established at the National Kidney Foundation conference on proteinuria, albuminuria, risk, assessment, detection, and elimination (PARADE). Pediatrics, 105, 1242-1249. doi:10.1542/peds.105.6.1242

[17] Haycock, G.B., Schwartz, G.J. and Wisotsky, D.H. (1978) Geometric method for measuring body surface area: A height-weight formula validated in infants, children, and adults. Journal of Pediatrics, 93, 62-66. doi:10.1016/S0022-3476(78)80601-5

[18] Kuczmarski, R.J., Ogden, C.L., Guo, S.S., Grummer-Strawn, L.M., Flegal, K.M., Mei, Z., Wei, R., Curtin, L.R., Roche, A.F. and Johnson, C.L. (2002) 2000 CDC growth charts for the United States: Methods and development. Vital and Health Statistics Series, 11, 1-190.

[19] Odeh, R.E., Chou, Y.M. and Owen, D.B. (1989) Sample size determination for two-sided beta-expectetion tolerance intervals for a normal distribution. Technometrics, 31, 461-468. doi:10.1080/00401706.1989.10488594

[20] Schreuder, M.F., Langemeijer, M.E., Bokenkamp, A., Delemarre-Van de Waal, H.A. and Van Wijk, J.A. (2008) Hypertension and microalbuminuria in children with congenital solitary kidneys. Journal of Paediatrics and Child Health, 44, 363-368. doi:10.1111/j.1440-1754.2008.01315.x

[21] Lou-Meda, R., Gilstrap, J., et al. (2007) Prognostic significance of microalbuminuria in postdiarrheal hemolytic uremic syndrome. Pediatric Nephrology, 22, 117-120. doi:10.1007/s00467-006-0283-3

[22] Maahs, D.M., Bell, M.S., et al. (2007) Higher prevalence of elevated albumin excretion in youth with type 2 than type 1 diabetes: The SEARCH for diabetes in youth study. Diabetes Care, 30, 2593-2598. doi:10.2337/dc07-0450

[23] Houser, M.T. (1987) Characterization of recumbent, ambulatory, and postexercise proteinuria in the adolescent. Pediatric Research, 21, 442-446. doi:10.1203/00006450-198705000-00004

[24] Brandt, J.R., Jacobs, A., Raissy, H.H., Kelly, F.M., Staples, A.O., Kaufman, E. and Wong, C.S. (2010) Orthostatic proteinuria and the spectrum of diurnal variability of urinary protein excretion in healthy children. Pediatric Nephrology, 25, 1131-1137.

[25] Nguyen, S., McCulloch, C., Brakeman, P., Portale, A., 
and Hsu, C.Y. (2008) Being overweight modifies the association between cardiovascular risk factors and microalbuminuria in adolescents. Pediatrics, 121, 37-45. doi:10.1542/peds.2007-3594

[26] Skinner, A.M., Addison, G.M. and Price, D.A. (1996) Changes in the urinary excretion of creatinine, albumin and $\mathrm{N}$-acetyl-beta-D-glucosaminidase with increasing age and maturity in healthy schoolchildren. European Journal of Pediatrics, 155, 596-602.

[27] Burgert, T.S., Dziura, J., Yeckel, C., Taksali, S.E., Weiss, R., Tamborlane, W. and Caprio, S. (2006) Microalbuminuria in pediatric obesity: Prevalence and relation to other cardiovascular risk factors. International Journal of Obesity, 30, 273-280. doi:10.1038/sj.ijo.0803136 